\title{
AVALIAÇÃo DA REINFECÇÃo PERITONEAL APÓS PERITONITE FECAL EM RATOS
}

\section{ASSESSMENT OF PERITONEAL REINFECTION AFTER FECAL PERITONITIS IN RATS}

\author{
Andy Petroianu,TCBC-MG ${ }^{1}$ \\ Bruno Gustavo Muzzi Carvalho e Carneiro ${ }^{2}$ \\ Fernando Henrique Oliveira Carmo Rodrigues ${ }^{3}$ \\ Renata Figueiredo Rocha ${ }^{4}$
}

\begin{abstract}
RESUMO: Objetivo: Há poucos estudos sobre os efeitos de uma nova infecção após peritonite séptica. Com o objetivo de compreender melhor esta situação, realizou-se o presente experimento tendo como parâmetro o papel do tempo neste fenômeno. Método: Foram utilizadas 36 ratas Wistar adultas, submetidas a peritonite fecal com injeção intraperitoneal de uma solução de fezes de ratos. Os animais foram divididos em quatro grupos $(\mathrm{n}=9)$ : Grupo 1A - controle: injeção intraperitoneal de solução de fezes com uma quantidade sabidamente letal $(10 \mathrm{ml} / \mathrm{kg})$; Grupo 1B - reinfecção: injeção intraperitoneal de solução de fezes com uma quantidade sabidamente não letal ( $2 \mathrm{ml} / \mathrm{kg}$ ) e, após 30 dias, injeção de solução de fezes $(10 \mathrm{ml} / \mathrm{kg})$; Grupo $2 \mathrm{~A}$ - controle da reinfecção tardia: injeção intraperitoneal de fezes a $10 \mathrm{ml} / \mathrm{kg}$; Grupo 2B - reinfecção tardia: injeção intraperitoneal de fezes a $2 \mathrm{ml} / \mathrm{kg}$ e, após quatro meses, injeção de 10ml $/ \mathrm{kg}$. Resultados: Todos os nove animais do Grupo $1 \mathrm{~A}$ morreram no período de sete dias após a injeção da solução de fezes. Já no Grupo 1B, pré-infectado, apenas um animal morreu, 24 horas após a injeção da solução de fezes a $10 \mathrm{ml} / \mathrm{kg}(\mathrm{p}<0,001)$. Em relação ao Grupo 2, oito dos nove animais de cada subgrupo morreram no período de sete dias. Conclusões: Uma sepse peritoneal menor por fezes eleva a resistência orgânica a nova contaminação fecal mais intensa que ocorra após um período curto. Contudo, essa defesa não persiste por tempo mais prolongado.
\end{abstract}

Descritores: Peritonite; Sepse; Infecção; Fezes; Imunidade; Ratos Wistar.

\section{INTRODUÇÃO}

A maioria das infecções peritoneais é causada por bactérias gram-negativas e anaeróbias, principalmente Escherichia coli e Bacteroides fragilis, respectivamente. A Escherichia coli predomina na fase aguda do processo. Na fase crônica, quando há a formação de abscessos, predominam as bactérias anaeróbias, principalmente Bacteroides fragilis, e Enterococcus, que agem em sinergismo. ${ }^{1-3}$
A associação entre sepse e peritonite ainda não está completamente esclarecida. Durante a fase aguda, após a invasão por bactérias gram-negativas, o organismo reconhece o lipopolissacarídio (LPS) e sua principal molécula, lípide A, como sinalizadoras da penetração bacteriana. ${ }^{4}$ A proteína plasmática LPB (lipopolysaccharide binding protein) transfere LPS ao CD14 na superfície de monócitos, macrófagos e neutrófilos ${ }^{5}$. Esse fenômeno provoca a produção e liberação de mediadores, tais como o fator de necrose

1. Professor Titular do Departamento de Cirurgia da Faculdade de Medicina, UFMG; Docente-Livre de Técnica Operatória e Cirurgia Experimental da Escola Paulista de Medicina, UNIFESP; Docente-Livre de Gastroenterologia Cirúrgica da Faculdade de Medicina de Ribeirão Preto, USP, Doutor em Fisiologia e Farmacologia pelo Instituto de Ciências Biológicas, UFMG; Pesquisador IA do CNPq.

2. Acadêmico da Faculdade de Medicina da UFMG; Bolsista de Iniciação Científica da FAPEMIG.

3. Acadêmico da Faculdade de Medicina da UFMG; Bolsista de Iniciação Científica do CNPq.

4. Acadêmica da Faculdade de Medicina da UFMG.

Recebido em 27/08/2002

Aceito para publicação em 18/02/2003

Trabalho realizado no Departamento de Cirurgia da Faculdade de Medicina da UFMG. 
tumoral (TNF) e as interleucinas 1, 6 e 8, gerando a amplificação do sinal do LPS no plasma e a sua transmissão a outras células e tecidos. ${ }^{6-8}$ Em associação com essas citocinas, ocorre a liberação de fatores derivados de fosfolipídios e de fatores de coagulação, ativação do complemento, aumento da permeabilidade do endotélio vascular e produção de óxido nítrico. ${ }^{9,10}$ Ressalta-se ainda a importância da resistência à infecção peritoneal por meio da ativação dos fatores de complemento $\mathrm{C} 3$ e $\mathrm{C} 4$, de mastócitos, do TNF e da imunoglobulina $\mathrm{M}(\operatorname{IgM}))^{9,11-14}$

A primeira linha de defesa a uma infecção peritoneal é a imunidade natural (neutrófilos, macrófagos e ativação do complemento $)^{8,15}$ e a imunidade adquirida específica aos patógenos invasores, por meio da ação da $\operatorname{IgM} .{ }^{9}$ A resposta da imunidade natural é ativada imediatamente após o estímulo antigênico, porém tem curta duração após o fim desse estímulo. Entretanto, a imunidade adquirida ainda persiste por mais tempo. A possível ativação de clones de células $T$ poderia gerar uma defesa imunitária mais prolongada e eficaz em infecções subseqüentes. Acredita-se que a imunidade humoral seja a principal resposta específica protetora contra bactérias em sua forma extracelular.

Há poucos estudos na literatura a respeito dos efeitos de uma nova infecção após uma peritonite séptica, mas seus resultados são conflitantes. ${ }^{10,16}$ De acordo com Feterowski et al, uma nova agressão ainda na fase aguda de um fenômeno séptico gera uma melhor resposta do organismo, caso seja feita após quatro dias da infecção inicial. A explicação para esse resultado foi a de que a exposição prévia ao LPS modularia a defesa do organismo mediante a amplificação da imunidade natural. A exposição prévia seria o fator responsável pela ativação e pelo aumento do número de neutrófilos, por inibição da apoptose, no local da infecção. ${ }^{10}$ Por outro lado, Zhou et al encontraram que a exposição ao LPS diminui o aporte de monócitos na cavidade peritoneal, por meio da regulação inibitória dos receptores CCR2 da superfície celular sangüínea periférica, gerando redução da resposta imune natural. ${ }^{16}$

$\mathrm{Na}$ revisão da literatura, não encontramos relatos a respeito dos resultados de reinfecções peritoneais após tempos maiores. Tais experimentos poderiam informar sobre a duração da imunidade adquirida e se haveria a formação e a persistência da defesa imunitária a esse tipo de quadro séptico.
A experiência cirúrgica tem mostrado que pacientes operados mais de uma vez em conseqüência de peritonite séptica, aparentemente evoluem melhor após operações subsequientes do que depois da primeira intervenção. Essa constatação não inclui as reoperações programadas para tratamento da peritonite grave, mas apenas os casos que apresentam múltiplos episódios sépticos abdominais.

Essas observações conduziram à hipótese de a peritonite séptica poder induzir a algum tipo de resistência orgânica a novas infecções abdominais. Para esclarecer esse fato, o presente trabalho teve por objetivo avaliar experimentalmente a mortalidade após um episódio de sepse abdominal e a influência de peritonite prévia em reinfecções abdominais realizadas em períodos iniciais e tardios, após o primeiro quadro séptico.

O presente trabalho foi realizado de acordo com as recomendações das Normas Internacionais de Proteção aos Animais e aprovado por Comissão de Ética do Departamento de Cirurgia da Faculdade de Medicina da Universidade Federal de Minas Gerais. ${ }^{17,18}$

\section{MÉTODO}

Foram utilizadas 36 ratas Wistar adultas, pesando entre 200 e 300 gramas, procedentes do Biotério da Faculdade de Medicina da UFMG. Os animais foram divididos aleatoriamente em quatro grupos $(\mathrm{n}=$ 9), de acordo com o seguinte protocolo:

Grupo 1A - controle: injeção intraperitoneal de solução de fezes com uma quantidade sabidamente letal, $10 \mathrm{ml} / \mathrm{kg}$, determinada em estudo piloto. Essa solução foi introduzida no mesmo dia da segunda injeção de solução fecal do Grupo 1B.

Grupo 1B - reinfecção: injeção intraperitoneal inicial com uma quantidade pequena de solução fecal, sabidamente não letal, $2 \mathrm{ml} / \mathrm{kg}$, de acordo com estudo piloto. Após 30 dias de acompanhamento, foi realizada nova inoculação de solução fecal na quantidade de $10 \mathrm{ml} / \mathrm{kg}$, a mesma injetada no Grupo 1A.

Grupo 2A - controle da reinfecção tardia: injeção intraperitoneal de solução de fezes na quantidade de $10 \mathrm{ml} / \mathrm{kg}$. Essa solução foi inoculada no mesmo dia da segunda injeção de solução fecal do Grupo 2B

Grupo 2B - reinfecção tardia: injeção intraperitoneal inicial da solução de fezes à $2 \mathrm{ml} / \mathrm{kg}$. Após 4 meses de acompanhamento, inoculou-se a mesma solução de fezes à $10 \mathrm{ml} / \mathrm{kg}$ injetada no Grupo $2 \mathrm{~A}$. 
A solução de fezes a $10 \%$ foi preparada colocando 2 gramas de fezes de rato em um frasco de Becker. Adicionou-se água suficiente para completar 20 mililitros. Essa mistura foi homogeneizada e filtrada através de gaze para remover as partículas fecais.

Os procedimentos foram conduzidos sob anestesia inalatória com éter etílico. A solução fecal foi injetada na cavidade peritoneal com auxílio de uma seringa com agulha de $25 \times 7$, ao nível da cicatriz umbilical, $0,5 \mathrm{~cm}$ à esquerda do músculo reto abdominal.

Os animais foram acompanhados diariamente e receberam dieta à base de ração para ratos e água, à vontade. Todos os animais foram seguidos pelo período determinado para o grupo ao qual pertenciam. As ratas que morreram foram submetidos a necrópsia.

Para a análise estatística utilizou-se o teste exato de Fisher. Os valores de p menores que 0,05 foram considerados significativos.

\section{RESULTADOS}

Todos os nove animais do Grupo 1A morreram no período de sete dias após a injeção da solução de fezes. Já no Grupo 1B, pré-infectado, apenas um animal morreu, após 24 horas; as outras oito ratas permaneceram vivas durante os 30 dias de acompanhamento. A diferença entre ambos os grupos foi de $\mathrm{p}<0,001$ (Tabela 1). Â necrópsia, em todos os animais de ambos os grupos foi encontrado abundante líquido turvo na cavidade abdominal. No Grupo 1B havia mais aderências peritoneais do que no Grupo 1A.

Em relação aos grupos $2 \mathrm{~A}$ e $2 \mathrm{~B}$, oito dos nove animais de cada grupo morreram no período de sete dias. Os outros dois ratos sobreviveram durante os 30 dias de acompanhamento. Não houve diferença no tempo de sobrevida entre as ratas de ambos os grupos. À necrópsia, constatou-se grande quantidade de líquido turvo em todos os animais de ambos os grupos (Tabela 1).

Ao compararem-se os grupos 1 e 2, observou-se que não houve diferença na mortalidade das 9 ratas do Grupo 1A com as 8 ratas do Grupo 2A. Por outro lado, a diferença entre a mortalidade da única rata do Grupo $1 \mathrm{~B}$ foi menor do que as 8 ratas que morreram no Grupo 2B ( $<<0,001)$ (Tabela 1).

\section{DISCUSSÃO}

O presente experimento mostra que, na reinfecção induzida após o período curto de um mês, a mortalidade foi muito menor do que a verificada no grupo controle. Esse resultado indica que a redução da mortalidade após a reinfecção seja, pelo menos em parte, devida à defesa imunitária adquirida na primeira infecção. Entretanto, essa proteção é apenas temporária, pois no grupo estudado após reinfecção tardia a mortalidade foi exatamente a mesma encontrada em seu grupo controle. Foram utilizados dois grupos-controle para assegurar que as duas soluções de fezes, utilizadas em tempos diferentes, eram de fato letais às ratas, que tinham idade e peso semelhantes nos grupos experimentais e seus respectivos controles.

A IgM tem a sua importância reconhecida na defesa do organismo contra a infecção bacteriana na peritonite, pela indução de respostas tanto locais quanto sistêmicas. ${ }^{14,15,19,20}$ Essa opsonina promove aumen-

Tabela 1 - Mortalidade de ratas submetidas a infecção intraperitoneal com solução fecal.

\begin{tabular}{|c|c|c|c|c|}
\hline \multirow[t]{3}{*}{ Grupo } & \multicolumn{2}{|c|}{1} & \multicolumn{2}{|c|}{2} \\
\hline & $\bar{A}$ & $\mathrm{~B}$ & $\bar{A}$ & B \\
\hline & $(n=9)$ & $(n=9)$ & $(n=9)$ & $(\mathrm{n}=9)$ \\
\hline No de animais mortos & 9 & $1 *$ & 8 & 8 \\
\hline \multicolumn{5}{|c|}{ Grupo $1 \mathrm{~A}$ - Infecção de solução fecal $10 \mathrm{ml} / \mathrm{kg}$. Acompanhamento por 7 dias. } \\
\hline \multicolumn{5}{|c|}{$\begin{array}{l}\text { Grupo } 1 \text { - Infecção de solução fecal } 10 \mathrm{ml} / \mathrm{kg} \text {. Acompanhamento por } 7 \text { dias. } \\
\text { Grupo } 1 B \text {-Infecção de solução fecal } 2 \mathrm{ml} / \mathrm{kg} \text {. Após } 30 \text { dias, injeção de } 10 \mathrm{ml} / \mathrm{kg} \text {. Acompanhamento por } 30 \text { dias após a segunda infecção. }\end{array}$} \\
\hline \multicolumn{5}{|c|}{ Grupo $2 \mathrm{~A}$ - Infecção de solução fecal $10 \mathrm{ml} / \mathrm{kg}$. Acompanhamento por 7 dias. } \\
\hline \multicolumn{5}{|c|}{ Grupo $2 B$-Infecção de solução fecal $2 \mathrm{ml} / \mathrm{kg}$. Após 4 meses, injeção de $10 \mathrm{ml} / \mathrm{kg}$. Acompanhamento por 7 dias após a segunda infecção. } \\
\hline
\end{tabular}


to dos níveis de TNF, IL-6 e neutrófilos, além de ativar a cascata do complemento, especialmente o $\mathrm{C} 3{ }^{6-14}$. Esse mecanismo possivelmente reduz a quantidade de E. coli peritoneal e de LPS sérico. ${ }^{19} \mathrm{~A}$ falta de IgM específica piora todos esses parâmetros, aumentando a mortalidade. ${ }^{9}$ É provável, portanto, que, após um mês, os níveis séricos de $\operatorname{IgM}$ e de outros fatores imunitários ainda estivessem elevados nos animais do Grupo 1B, o que não deve ter ocorrido com os animais do Grupo 2B, que não tiveram uma resposta adequada à nova agressão bacteriana. Todavia, não foi objetivo do presente trabalho estudar essas hipóteses. Diante dos resultados encontrados, é fundamental prosseguir as investigações dentro da mesma linha de pesquisa, para compreender o mecanismo de defesa induzido pela peritonite e que protege o organismo em caso de reinfecção peritoneal.

O fato de a reinfecção tardia ter sido seguida de elevada mortalidade sugere que a defesa orgânica adquirida, que havia sido eficaz para controlar a peritonite decorrente de reinfecção em período inicial, não perdurou. Isto mostra que a resposta imune a essa infecção provavelmente não depende de linfócitos T, o que poderia explicar essa não indução de memória imunológica. ${ }^{15,19,20}$

Os resultados do presente estudo estão de acordo com as observações cirúrgicas prévias em pacientes com múltiplos episódios de peritonite sépti- ca. De fato, os animais submetidos a reinfecções após curto período de tempo apresentam uma evolução muito melhor do que os que tiveram apenas uma infecção abdominal maior ou os que foram reinfectados depois de um período mais prolongado. Cabe ressaltar, portanto, que, se de fato uma sepse abdominal menor induz à resistência orgânica a novo episódio séptico, tal situação é transitória, pois após um período longo, a mortalidade pela reinfecção voltou a ser grande.

Apenas os dados dessa pesquisa são insuficientes para extrapolar-se uma teoria maior. Na mesma linha de pesquisa experimental, serão estudados em trabalhos vindouros os níveis séricos de diferentes mediadores encontrados em quadros sépticos graves, como as interleucinas e o fator de necrose tumoral.

Portanto, uma sepse peritoneal menor por solução fecal eleva a resistência orgânica a nova contaminação fecal mais intensa, que ocorra após um período curto. Contudo, essa defesa não persiste por tempo prolongado.

\section{AGRADECIMENTOS}

Os autores agradecem ao CNPq e à FAPEMIG pelos auxílios financeiros, que possibilitaram a realização deste trabalho.

\begin{abstract}
Background: Few studies are available addressing the effects of a new infection after septic peritonitis. Thus, the present study was conducted with the objective to better understanding this situation using the role of time in this phenomenon as a parameter. Methods: Thirty-six adult female Wistar rats were submitted to fecal peritonitis by an intraperitoneal injection of a solution of rat feces. The animals were divided into 4 groups $(n=9$ each): Group $1 A$ - control: intraperitoneal injection of an amount of fecal solution known to be lethal (10 ml/kg); Group $1 B$ - reinfection: intraperitoneal injection of an amount of fecal solution known not to be lethal $(2 \mathrm{ml} / \mathrm{kg})$ followed by an injection of fecal solution $(10 \mathrm{ml} / \mathrm{kg}) 30$ days later; Group $2 \mathrm{~A}$ - control of late reinfection: intraperitoneal injection of $10 \mathrm{ml} / \mathrm{kg}$ feces; Group $2 \mathrm{~B}$ - late reinfection: intraperitoneal injection of $2 \mathrm{ml} / \mathrm{kg}$ feces followed by an injection of $10 \mathrm{ml} / \mathrm{kg} 4$ months later. RESULTS: All nine animals in Group 1A died within seven days after injection of the fecal solution. In contrast, in the preinfected Group $1 B$ only 1 animal died ( $p<0.001) 24$ hours after injection of the fecal solution $(10 \mathrm{ml} / \mathrm{kg})$. With respect to Group 2, eight of the nine animals in each subgroup died over a period of 7 days. Conclusions: Milder peritoneal sepsis due to fecal infection raises the organic resistance to a new more intense fecal contamination occurring after a short period of time. However, this defense does not persist over a more prolonged period of time.
\end{abstract}

Key Words: Peritonitis; Sepsis; Infection; Feces; Immunity; Rats, Wistar. 


\section{REFERÊNCIAS}

1. Carneiro BGMC, Petroianu A, Rodrigues FHOC, et al. Estudo comparativo entre diversos tipos de tratamento para peritonite fecal em rato. Rev Col Bras Cir, 2002, 29:43-48.

2. Gorbach SL - Treatment of intra-abdominal infections. J Antimicrob Chemother, 1993, 31 (Suppl A): 67-78.

3. Wittmann DH, Schein M, Condon RE - Management of secondary peritonitis. Ann Surg, 1996, 224(1):10-8.

4. Rietschel ET, Brade H - Bacterial endotoxins. Sci Am, 1992, 267(2):54-61.

5. Tobias PS, Mathison J, Mintz D, et al. - Participation of lipopolysaccharide-binding protein in lipopolysaccharide-dependent macrophage activation. Am J Respir Cell Mol Biol, 1992, 7(3):239-245.

6. Lynn WA - Anti-endotoxin therapeutic options for the treatment of sepsis.J Antimicrob Chemother, 1998, 41(Suppl A): 71-80.

7. Scapini P, Lapinet-Vera JA, Gasperini S, et al. - The neutrophil as a cellular source of chemokines. Immunol Rev, 2000, 177:195-203.

8. Sikora JP - The role of cytokines and reactive oxygen species in the pathogenesis of sepsis. Pol Merkuriusz Lek, 2000, 7(43): 47-50.

9. Boes M, Prodeus AP, Schmidt T, et al. - A critical role of natural immunoglobulin $\mathrm{M}$ in immediate defense against systemic bacterial infection. J Exp Med, 1998, 188(12):2381-2386.

10. Feterowski C, Weighardt H, Emmanuilidis K, et al. Immune protection against septic peritonitis in endotoxin-primed mice is related to reduced neutrophil apoptosis. Eur J Immunol, 2001, 31(4):1268-1277.

11. Echtenacher B, Männel DN, Hultner L - Critical protective role of mast cells in a model of acute septic peritonitis. Nature, 1996, 381(6577):75-77.
12. Malaviya R, Ikeda T, Ross E, et al. - Mast cell modulation of neutrophil influx and bacterial clearance at sites of infection through TNF-alpha. Nature, 1996, 381(6577): 77-80.

13. Prodeus AP, Zhou X, Maurer M, et al. - Impaired mast cell-dependent natural immunity in complement C3deficient mice. Nature, 1997, 390(6656):172-175.

14. Tracey KJ, Fong Y, Hesse DG, et al. - Anticachectin/ TNF monoclonal antibodies prevent septic shock during lethal bacteraemia. Nature, 1987, 330(6149):662-664.

15. Szczepanik M, Gryglewski A, Solecki R - Defense mechanisms in the peritoneum. Przegl Lek, 1999, 56(3):227-230.

16. Zhou Y, Yang Y, Warr G, et al. - LPS down-regulates the expression of chemokine receptor CCR2 in mice and abolishes macrophage infiltration in acute inflammation. J Leukoc Biol, 1999, 65(2):265-269.

17. Cooper JE - Ethics and laboratory animals. Vet Rec, 1985,116(22):594-595.

18. Petroianu A - 'Pesquisa experimental". In Petroianu A (ed) - Ética, Moral e Deontologia Médicas. Rio de Janeiro. Guanabara Koogan, 2000, pp. 185-190.

19. Bennett-Guerrero E, McIntosh TJ, Barclay GR, et al. Preparation and preclinical evaluation of a novel liposomal complete-core lipopolysaccharide vaccine. Infect Immun, 2000, 68(11):6202-6208.

20. Kasper DL, Onderdonk AB - Infection with Bacteroides fragilis: pathogenesis and immunoprophylaxis in an animal model. Scand J Infect Dis, 1982, Suppl 31:28-33.

Endereço para correspondência:

Prof. Andy Petroianu

Av. Afonso Pena, 1626 - apto. 1901

30130-005 - Belo Horizonte, MG.

FONE/FAX: (31) 3274-7744

e-mail: petroian@medicina.ufmg.br 